\title{
The Conundrum of Talent Training of Industrial Big Data Analysis in China's E-Commerce Talent Cultivating System
}

\author{
Rui Bai ${ }^{1}$, Weiyu Pan ${ }^{2}$, Juan $\mathrm{Xu}^{2}$, Lin Lei ${ }^{3}$, Xiaojing $\mathrm{Wu}^{* 4}$ \\ ${ }^{I}$ Situation and Policy Research Department, Nankai University, Tianjin, China \\ ${ }^{2}$ Economics and Management School, Guang 'an Vocational \& Technical college, Guang 'an, Sichuan, \\ China \\ ${ }^{3}$ School of Culture and Tourism, Chengdu Vocational \& Technical college, Chengdu, Sichuan, China \\ ${ }^{4}$ College of Political Science, Chengdu Normal University, Chengdu, Sichuan, China \\ *Corresponding Author.
}

\begin{abstract}
With the development of information technology, Industrial Big Data Analysis (BDA) has become the most important link in China's E-commerce, but the development of BDA in China's E-commerce has been greatly restricted by talents. The main reason is that the specialty of Industrial BDA and the practicality of E-commerce are difficult to be well integrated in China's existing education system, which is due to the very special development history of E-commerce in China. The training of talents for E-commerce BDA has become a structural problem in China.
\end{abstract}

Keywords: BDA, Industrial, E-commerce, education

\section{Introduction}

With the rapid development of computer technology in recent years, in the economic field, Big Data Analysis (BDA) enables E-commerce companies to use data more effectively and accurately, improve the conversion rate of production and service, and improve decision making and user power. BDA has increasingly become an indispensable element in economy, finance, business and trade. The combination of E-commerce and big data, including feedback analysis of customers' habits and preferences, has become a new business model [1]. Professionals in computer science and data analytics also earn more in China than in any other industry. This is not only closely related to the current economic development, but also related to the core task of the 2025 plan advocated by the Chinese government: to promote the strategy of in-depth integration of informatization and industrialization. Therefore, we can see that both entertainment platforms such as TikTok and Kuaishou, and social and film platforms such as WeChat, Weibo and Bilibili also use big data to promote. One factor that cannot be ignored is that since 2020, the world has been plagued by the COVID-19 Pandemic, which has made a huge change in people's accustomed way of life and will certainly have a lasting impact on our daily life in visible time [2]. As a result, the E-commerce sector, for which there is already a growing demand, has become even more important. In any respect, and for both China and the world, E-commerce has come back to a very mainstream position in recent years. And the core of today's e-business is BDA, which provides increasing value to decision making and business problem solving by utilizing the dynamic changes of people, processes and technologies to transform data into visualizations [3]. However, Chinese academic circles have not paid enough attention to E-commerce for a long time, so that the teaching of E-commerce has been seriously divorced from the actual needs of today's society. In this paper, we analyze the weaknesses of E-commerce teaching in China in light of the characteristics of today's big data, so as to encourage others to offer insights, so that more peers can pay attention to and can quickly correct the corresponding mistakes.

\section{The 5V Characteristics of Big Data and its Sinicization}

ISSN: 0010-8189

(C) CONVERTER 2020

www.converter-magazine.info 
IBM has simplified the characteristics of big data into 5V, namely Volume, Velocity, Variety, Value (low value density), and Veracity. The 'Volume' trait introduces new 'agile' analytics and machine learning techniques, and increases the speed of data processing and analysis. Therefore, E-commerce companies must have the ability to embed analytics and optimization into their operations and decision-making processes to increase their speed and impact [3]. 'Variety' is another key element of big data because they are generated from a variety of sources and formats, including text, Web, social media, audio, video, clickstreams, log files, etc [4]. This type of data requires the use of different analytical and predictive models that can use information about different functional domains [5]. 'Velocity' refers to the speed of change of big data and the speed at which big data is applied in business decisions in order to increase value [6]. 'Veracity' is an important requirement for BDA to achieve better predictability in an E-commerce environment [7]. In fact, data has the potential to open up new opportunities for businesses if greater data speeds can be guaranteed. Therefore, in the context of big data, the word 'Value' means that benefits with economic value can be generated through the extraction and transformation of big data [8]. In China, the application of big data is mainly conducted by enterprises, especially Internet enterprises, such as Baidu, Tencent, Alibaba, Jingdong, etc. Although these companies undertake a variety of businesses, most of them have E-commerce as their main business. Take Alibaba Group and Jingdong for example: although Alibaba Group has developed businesses including payment, its Taobao is still the main business. Jingdong has built its entire corporate ecosystem on the basis of its E-commerce platform. Among them, the analysis and application of big data provides important support for various fields from the collection and pushing of consumer-related data to the construction of supply chain platforms and logistics ports. The collection and application of user-oriented big data inevitably involves personal privacy and human rights issues. These difficulties are a very sensitive topic in the developed capitalist society, so the analysis of big data on consumers is greatly restricted from the source. However, in China, due to the lag in relevant regulations and the Chinese cultural tradition of not placing much importance on personal privacy, many behaviors that are seen as invasions of privacy in Western societies are considered customary in China since ancient times. Problems related to the collection of customer information data are not a serious problem in China. Therefore, the business of BDA in China's E-commerce is tacitly permitted to some extent, as long as it does not involve large-scale data leakage of users. Therefore, in terms of application level, China may lead the world in the application of BDA in E-commerce.

\section{Five Weaknesses of China's E-Commerce Education at the Present Stage}

Although the application of BDA in E-commerce in China is very avant-garde, the teaching of BDA in E-commerce is very backward. This kind of backwardness is a cross-age backwardness, among which the reasons are more complex. This paper divides the main problems existing in China's E-commerce education into five weaknesses:

Discrimination against E-commerce: E-commerce was a very popular major around 2005, and colleges and universities have set up related majors. But then came the saturation of the market and employment irregularities. E-commerce is mainly dominated by small workshops, which are very informal. As a result, society has a lot of discrimination against E-commerce. Therefore, universities and colleges no longer offer E-commerce as a major, but turn to vocational and technical colleges to offer it. However, vocational and technical colleges have a very low status in the minds of Chinese people, which also leads to the fact that most people think that E-commerce is a "non-mainstream" and "no future" major. This is discrimination against E-commerce from society to academia.

Underestimation of students' ability: E-commerce majors are mainly undertaken by vocational and technical colleges, which are considered to be "not promising". Vocational and technical colleges have a very low social status in China because most of their students are those who failed the college entrance exam, or even those who did not attend high school. China's education is mainly based on academic performance to measure the quality of students [9], so society tends to have a stereotype of "low IQ" for such students, which even spreads to the teachers and management level of vocational and technical colleges. With this kind of stereotype, the depth and breadth of teaching will be seriously affected, which will lead to a serious underestimation of students' ability. 
Weakness of faculty: Because of the social status of vocational and technical colleges, the teaching staff are often not among the industry elite. In addition, the administrative level of management is very backward, the teachers who come to teach are not in the same major, and the employment must go through a very rigid process (for example, the major must be related, but the institutions that offer majors related to E-commerce are not the top institutions in China at present), and the salary is low. Therefore, despite the practice of introducing talents such as PhDs in developed regions such as Shenzhen in recent years, they are often not practitioners and researchers in E-commerce and often do not participate in teaching, so this does not change the dilemma of overall faculty decline.

Dogmatic teaching system: The teaching of E-commerce still follows a very old and too dogmatic teaching system, and its understanding and practical training of E-commerce are mainly focused on doing traditional logistics, that is, being a mail courier. And even modern logistics has entered the era of big data. Therefore, in today's rapidly changing information age, the gap brought about by the dogmatic teaching system is an epoch-crossing gap. Just like the characteristics of the information age, the technology and framework of two years ago can be considered to be backward.

Apparent defects of teaching materials: Since BDA is advocated in China, and E-commerce companies have promoted BDA everywhere, vocational and technical colleges have responded to it. This response is mainly reflected in the teaching materials, but it is very negative. The textbooks used are indeed the professional textbooks of the vocational and technical colleges at the national level, but the defects of such textbooks are also very obvious. Take Guang 'an Vocational and Technical College as an example: in the part of big data processing or business data analysis, the courses and textbooks taught throughout the semester are all based on Excel as the only teaching tool. Other than examples and software versions, the tutorial is no different than it was 20 years ago. In the training of E-commerce related network marketing, students are taught to write advertorials and do live broadcasting. This is just because web celebrities are relatively popular in China, and later they sell products to fans.

\section{Based on the 5V Characteristics of Big Data to See the Weaknesses of E-Commerce Education}

Since the biggest challenge in E-commerce is how to handle and analyze the huge amount of data [10], the best place to meet this need is in schools. We can see that there is a huge gap between the teaching level and the reality of E-commerce in China. Obviously, these problems are structural and cannot be solved by simple treatment. In the case of the application of big data in E-commerce, there is a mismatch between technology and theory. Most of the institutions that have the ability to carry out BDA are well-known undergraduate institutions, but most of them have abandoned the E-commerce major for a long time. So one of the most common forms nowadays is school-to-school or college-to-college alliances. For example, Southwestern University of Finance and Economics and University of Electronic Science and Technology of China have jointly set up a big data research center. But the effect is not significant, and student training is a big problem. As for the vocational and technical colleges that have always maintained the specialty of electronic commerce, the biggest weakness lies in the outdated use of technology and teaching materials, especially in the western regions. In order to cope with big data analysis, teaching uses Excel. However, Excel is obviously not suitable for BDA because it is completely unable to cope with the characteristics of big data except for the factual characteristic of veracity. A direct consideration to change this would be to change the textbook. But replacing textbooks requires a series of process changes and faculty engaged in relevant research to match them. The existing faculty of E-commerce in vocational and technical colleges are often not competent for such complex and specialized courses that are updated quickly, and these courses do not allow teachers to teach what they learn instantly to students (this situation is very common in Chinese vocational and technical colleges, especially those in the backward areas of the central and western regions). A complete change would require a major overhaul of the entire system, which is much more difficult to achieve. Therefore, although E-commerce companies have increased their efforts to directly invest in supporting 
colleges and universities (for example, Jingdong Digital has signed a school-enterprise cooperation agreement with the School of Economics and Management of Guang'an Vocational and Technical College, and has supported the construction of facilities such as teaching buildings, teaching equipment, and whole industry chain workshops. This kind of industry-education integration is very common in the case of direct support from E-commerce enterprises for their own needs), but the results are very limited, and most of the students trained still do not have the mindset of BDA and the corresponding operation ability.

\section{Conclusion}

This paper introduces the rapid development of computer technology and E-commerce in China, and points out that the development and demand of BDA of E-commerce in China is very rapid, but the education and talents are far from keeping pace with the current situation; For undergraduate colleges, they have skills but no majors, while for vocational and technical colleges, they have majors but no skills, although they have closer ties and cooperation with enterprises. So this situation creates a huge gap. For this huge gap, China's E-commerce enterprises and related vocational and technical colleges have also made corresponding adjustments, but with little effect. Because such problems are structural, they cannot be solved by simple integration. How to improve is very difficult, and the principles and solutions need to be discussed by scholars later, so this paper is only intended to stimulate their thinking.

\section{Acknowledgements}

1. The general project of Guang' an Vocational \& Technical College, Based on the background of the integration of industry and education, the study on the school-enterprise "Dual" education model of E-Commerce major (GAZYKY-2021A11).

2. Fundamental Research Funds for the Central Universities of Southwestern University of Finance and Economics, How to Become a Successful Person: A Study on the Personal Life History of Yi Rural Youth (JBK2103008).

\section{References}

[1] L. Lei, T. Chi, T. Hao, et al., "Customer demand analysis of the electronic commerce supply chain using Big Data," Annals of Operations Research, vol. 268, no. 1-2, pp. 113-128, 2018.

[2] W. Y. Pan, R. Bai, C. Li, "The Real: Analysis of COVID-19 pandemic from the perspective of psychoanalysis," Paper presented at the Basic \& Clinical Pharmacology \& Toxicology, 2021.

[3] Akter, Shahriar, Wamba, et al., "Big data analytics in E-commerce: a systematic review and agenda for future research,” Electronic Markets the International Journal on Networked Business, 2016.

[4] P. Russom, Managing Big Data, 2013.

[5] S. Biesdorf, D. Court, P. Willmott, "Big data: What's your plan?" Mckinsey Quarterly, no. 2, pp. 40-51, 2013.

[6] G. Brain, "Top 5 Myths About Big Data". Retrieved from https://mashable.com/2012/06/19/big-data-myths/

[7] M. Schroeck, R. Shockley, J. Smart, et al., "Analytics: the real-world use of big data: how innovative enterprises extract value from uncertain data," Executive Report, 2012.

[8] D. Zeng, R. Lusch, "Big data analytics: perspective shifting from transactions to ecosystems," Intelligent Systems, IEEE, vol. 28, no. 2, pp. 2-5.

[9] R. Bai, W. Pan, J. Chen, et al., "Research on the academic performance of Chinese junior high school students from the perspective of Lacan's" family environment analysis"--multiple linear regression model based on CEPS data," Design Engineering, 293-309, 2021.

[10] S. S. Alrumiah, M. Hadwan, "Implementing big data analytics in e-commerce: vendor and customer view" IEEE Access, no. 99, pp. 1-1, 2021. 